\title{
Maximum Surgical Blood Order Schedule (MSBOS) for Cardio - Thoracic \& Vascular Interventions in an Apex Tertiary Care Hospital of India
}

\author{
Dr Sukhpal Singh ${ }^{1}$, Dr Narinder Kumar ${ }^{2}$, Dr Mahesh Mahla ${ }^{3}$, Dr Raman Sharma ${ }^{4}$, Dr Ashok Kumar \\ ${ }^{1}$ Senior Resident, Department of Hospital Administration, AIIMS, New Delhi \\ ${ }^{2}$ Senior Resident, Department of Hospital Administration, AIIMS, New Delhi \\ ORCID: https: //orcid. org/0000 - 0003 - 2795 - 9177 \\ Corresponding Author Email: narinder. aiims[at]gmail.com \\ ${ }^{3}$ Senior Resident, Department of Hospital Administration, PGIMS, Rohtak, Haryana \\ ${ }^{4}$ Associate Professor, Department of Hospital Administration, PGIMER, Chandigarh \\ ${ }^{5}$ Professor, Department of Hospital Administration, PGIMER, Chandigarh
}

\begin{abstract}
Background: Since the time of use of blood and blood products in medical and surgical interventions, its utilization is a point of debate. Over demanding of blood from blood bank services may lead to aging of blood and wastage of blood units. It also negatively impacts on the services of blood bank. There are various indices to estimate the utilization of blood services in a healthcare institute. Methods: In this study we have analysed 4 months blood bank data for CTVS interventions. Total 252 patients were involved. We have analysed the utilization of PRBC for the cardiac surgeries. Also, we have formulated MSBOS from the available data. Results: Results of this study shows, total 1006 units of PRBC were demanded for the surgeries, 784 units were issued by the blood - bank of the hospital and out of which $60 \%$ (472 units) were transfused to the patients. C/T ratio was less than 2.5 in majority of the surgeries, T\% was more than $30 \%$ in all the cases, and TI was greater than 0.5 in all surgeries. These figures show the significant requirement of blood in cardiac surgeries. Further, there was optimal utilization of blood in the institute.
\end{abstract}

Keywords: Blood utilization, Cardiac surgeries, MSBOS, blood transfusion, transfusion indices

\section{Introduction}

Blood transfusion is a vital element of healthcare system. Millions of lives are saved each year through blood transfusions. Shortfalls in blood supply contribute substantially to the burden of morbidity and mortality (1). Transfusion medicine is a complex, erudite medical discipline that makes possible many major surgeries as well as many modern medical therapies. An efficient Transfusion services in any hospital is a vital part of health care delivery mechanisms to achieve availability of sufficient, safe, affordable blood products (2). An accurate estimate for blood requirement is essential to ensure readiness of sufficient blood for patient care and to ensure evidence based policies in hospital blood transfusion services. Maintaining a sufficient supply and ensuring its appropriate utilization have been a great challenge for developing countries (3). The importance of appropriate utilization has focused researchers to study the blood ordering and utilization and revealed that blood requests sometimes are inflated than the actual requirement. This inflated demand, not only increase the workload of blood bank staff, but also leads to depletion of blood bank resources (4). Ultimately contributes to health and economic loss. Friedman et al. had given MSBOS concept in 1976 with main objective to save blood for transfusion and to standardize blood ordering practices. In their study MSBOS was formulated for 60 elective surgical conditions, Cardiac Surgeries were not included due to different types of procedures and high blood requirements at that time. The MSBOS is an effort to synchronize the amount of blood cross - matched and the amount which actually will be transfused (5).

In this study we have analysed the ordering requests of Packed red blood cells (PRBC) received in the department of Transfusion medicine from the Department of Cardiothoracic \& Vascular Surgery for planned surgeries. The actual utilization of the PRBC was studied and a MSBOS for the CTVS interventions was formulated.

\section{Material and Methods}

This is a descriptive cross - sectional Study which was conducted at Postgraduate Institute of Medical Education and Research (PGIMER) Chandigarh. Prospective data of 4 months for all elective surgery patients in Advance Cardiac Centre (ATC) was collected for January to April 2019. Total 252 patients were fulfilling the inclusion criteria were included in the study.

Inclusion criteria

Any patient in the specified period for whom whole blood / Packed RBC request will be made for the purpose of CTVS interventions. 


\section{International Journal of Science and Research (IJSR)

\section{Data analysis}

The collected data were entered into Microsoft Excel software. Data cleaning was done before the data analysis. Descriptive statistics including tables for frequencies, percentages, means, and ratios were used for analyses. The 20 types of planned surgeries as mentioned in Table 1 was recorded.

Table 1: Details of surgeries included in study and their frequency.

\begin{tabular}{|c|l|c|}
\hline $\begin{array}{c}\text { S. } \\
\text { No. }\end{array}$ & \multicolumn{1}{|c|}{ Surgery } & $\begin{array}{c}\text { Frequency } \\
(\%)\end{array}$ \\
\hline 1 & Coronary Artery Bypass Graft (CABG) Surgery & $37(14.7)$ \\
\hline 2 & Thoracotomy & $25(9.9)$ \\
\hline 3 & Atrial Septal Defect (ASD) Closure & $25(9.9)$ \\
\hline 4 & Tetralogy of Fallot (TOF) intracardiac repair (ICR) & $25(9.9)$ \\
\hline 5 & Mitral Valve Replacement (MVR) & $24(9.5)$ \\
\hline 6 & Atrial Valve Replacement (AVR) & $22(8.7)$ \\
\hline 7 & Double Valve Replacement (DVR) & $19(7.5)$ \\
\hline 8 & ICR and bidirectional (BD) Glenn & $18(7.1)$ \\
\hline 9 & Ventricular Septal Defect (VSD) Closure & $14(5.6)$ \\
\hline 10 & CABG and Valve Repair & $14(5.6)$ \\
\hline 11 & Other Cardiac Surgeries & $29(11.5)$ \\
\hline & Total & 252 \\
\hline
\end{tabular}

The following formulae were used to calculate $\mathrm{C} / \mathrm{T}$ ratio, Transfusion Probability (T\%), Transfusion Index (TI) and MSBOS:

- Calculation of $\mathrm{C} / \mathrm{T}$ ratio $=$ No. of units cross - matched $/$ No. of units transfused

- Transfusion Probability $(\mathrm{T} \%)=($ No. of patient transfused / No. of patients cross - matched) x 100.

- Transfusion Index (TI) = number of units transfused / number of patients cross matched.

- MSBOS was formulated using Mead's criterion* which is one and half times the TI for each surgical procedure.

\section{Ethics statement}

Approval for this study was obtained from the institutional ethics committee of Postgraduate Institute of Medical Education and Research (PGIMER) Chandigarh.

\section{Results}

This study was performed with 252 patients which had elective surgeries during January to April 2019. Table 2 illustrate the profile of patients, which shows $58.7 \%$ were male and $41.3 \%$ were females, $28.6 \%$ were paediatric patients. $\mathrm{AB}+\mathrm{ve}$ Blood group was found to be most common (38.1\%) followed by A +ve (23.4). Mean value of $\mathrm{Hb}$ before surgery was $13.2 \pm 2.7$, which was comparatively higher in male population.
Table 2: Profile of the patients

\begin{tabular}{|l|l|}
\hline Characteristic & Frequency (\%) \\
\hline Gender distribution & \\
\hline Male & $148(58.7)$ \\
\hline Female & $104(41.3)$ \\
\hline Age & $72(28.6)$ \\
\hline 0 - 14 years & $180(71.4)$ \\
\hline 15 and above & \\
\hline Blood Group & $59(23.4)$ \\
\hline A +ve & $3(1.2)$ \\
\hline A - ve & $26(10.3)$ \\
\hline B +ve & $1(0.4)$ \\
\hline B - ve & $96(38.1)$ \\
\hline AB +ve & $3(1.2)$ \\
\hline AB - ve & $61(24.2)$ \\
\hline O +ve & $3(1.2)$ \\
\hline O - ve & \\
\hline Hb before surgery & $13.2 \pm 2.7$ \\
\hline Mean & 12.9 \\
\hline Median & \\
\hline Males (n=148) & $13.7 \pm 2.4$ \\
\hline Mean & 13.5 \\
\hline Median & \\
\hline Females (n=104) & $12.6 \pm 2.8$ \\
\hline Mean & 12.1 \\
\hline Median & \\
\hline & \\
\hline
\end{tabular}

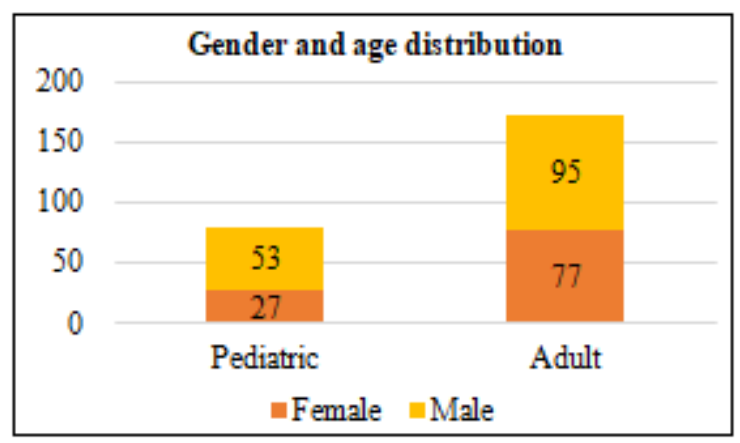

Figure 1: Chart showing gender and age relationship

\section{Blood Utilization profile}

Among the study population, 1006 units of PRBC were requested, 784 units were issued from the blood bank and 472 units were transfused to patients. It shows CABG and Valve Repair had maximum number of blood transfusion $(100 \%)$ whereas Thoracotomy was the least $(36 \%)$. A trend was observed in the No. of blood units ordering and issuing. It was observed that there is a pattern of ordering 4 units of blood (per patient) for all surgeries and blood bank issues 3 units of blood (per patient).

Table 3: Blood utilization profile of patients

\begin{tabular}{|c|c|c|c|c|c|}
\hline Surgery & Frequency & Patients transfused (\%) & PRBC requested & PRBC issued & PRBC units Transfused (\%) \\
\hline CABG Surgery & 37 & $36(97.3)$ & 148 & 116 & $92(79.3)$ \\
\hline Thoracotomy & 25 & $9(36)$ & 100 & 78 & $17(21.8)$ \\
\hline ASD Closure & 25 & $19(76)$ & 99 & 75 & $30(40)$ \\
\hline TOF ICR & 25 & $20(80)$ & 99 & 80 & $39(48.7)$ \\
\hline MVR & 24 & $22(91.7)$ & 96 & 72 & $50(69.4)$ \\
\hline AVR & 22 & $21(95.4)$ & 88 & 68 & $48(70.6)$ \\
\hline DVR & 19 & $17(89.4)$ & 76 & 59 & $37(62.7)$ \\
\hline ICR and BD Glenn & 18 & $15(83.3)$ & 72 & 55 & $32(58.2)$ \\
\hline VSD Closure & 14 & $13(92.8)$ & 56 & 43 & $28(65.1)$ \\
\hline
\end{tabular}

\section{Volume 10 Issue 11, November 2021}


International Journal of Science and Research (IJSR)

ISSN: 2319-7064

SJIF (2020): 7.803

\begin{tabular}{|c|c|c|c|c|c|} 
CABG and Valve Repair & 14 & $14(100)$ & 56 & 42 & $35(83.3)$ \\
\hline Other Surgeries & 29 & $25(86.2)$ & 116 & 96 & $64(78.9)$ \\
\hline Total & 252 & $211(83.7)$ & 1006 & 784 & $472(60.2)$ \\
\hline
\end{tabular}

\section{Blood utilization indices}

In our study, it was observed that overall cross match to transfusion ratio $(\mathrm{C} / \mathrm{T}$ ratio) was lesser than 2.5 ; transfusion probability (T\%) was greater than $30 \%$ and transfusion index (TI) was greater than 0.5 . These findings indicated that the overall blood utilization among patient's undergone CTVS interventions in the hospital was significant. $\mathrm{C} / \mathrm{T}$ ratio of 2.5 or below, T\% value of more than 30 and TI values more than 0.5 indicates a significant need for blood during surgery (6). The details are depicted in Table 4.

Table 4: Blood utilization indices of the patients

\begin{tabular}{|c|c|c|c|c|}
\hline Surgery & Frequency & C/T Ratio & T\% & TI \\
\hline CABG & 37 & 1.26 & 97.30 & 2.49 \\
\hline Thoracotomy & 25 & 4.59 & 36.00 & 0.68 \\
\hline ASD Closure & 25 & 2.50 & 76.00 & 1.20 \\
\hline TOF ICR & 25 & 2.05 & 80.00 & 1.56 \\
\hline AVR & 24 & 1.44 & 91.67 & 2.08 \\
\hline DVR & 22 & 1.42 & 95.45 & 2.18 \\
\hline MVR & 19 & 1.59 & 89.47 & 1.95 \\
\hline ICR and BD Glenn & 18 & 1.72 & 83.33 & 1.78 \\
\hline VSD Closure & 14 & 1.54 & 92.86 & 2.00 \\
\hline CABG and Valve Repair & 14 & 1.20 & 100.00 & 2.50 \\
\hline Other Surgeries & 29 & 1.50 & 86.21 & 2.21 \\
\hline
\end{tabular}

Table 5: Average and Standard deviation of the indices

\begin{tabular}{|l|l|l|}
\hline Variable & Mean & SD \\
\hline Request PRBC units & 91.45 & 26.74 \\
\hline Cross - matched units & 71.27 & 21.98 \\
\hline Transfused units & 42.91 & 20.55 \\
\hline C/T Ratio & 1.89 & 0.97 \\
\hline Transfusion probability (T\%) & 84.39 & 17.66 \\
\hline Transfusion Index (TI) & 1.87 & 0.55 \\
\hline
\end{tabular}

\section{Maximal Blood Ordering Schedule (MSBOS)}

MSBOS was formulated using Mead's criterion (6) which is 1.5 times the transfusion index (TI) for each surgical procedure and is depicted in Table 4. Mead's criterion provides Blood Ordering Quotient (BOQ) 1.5 times the average number of units transfused per transfused patient for the procedure. It is applicable only for those procedures with transfusion requirements similar enough so that the average amount transfused is within 1.5 times the average amount cross - matched for the procedure. Blood ordering quotient (BOQ) represents a ratio between the average number of units cross - matched per patient for a particular procedure and the average number of units transfused per patient.

\section{Discussion}

There is a general tendency to over - demand blood units in surgeries. It leads to holding up of blood bank reserve, aging of blood units and wastage of blood bank resources. Blood transfusion plays an important role in the resuscitation and management of surgical patients. But over - ordering as well as under - ordering both are not standard practices. The main goal of formulating MSBOS is to make pre - operative PRBC orders more closely coincide with the number of units of PRBC which will be transfused to patients undergoing elective surgeries (5). So, to increase the utilization of blood bank services. This study was restricted to the surgeries of CTVS interventions and included both paediatric as well as adult patients. In our study we observed that transfusion probability was more than $30 \%$ in all the cases, it was lowest in thoracotomy (36\%). This shows that CTVS interventions in our hospital had higher requirement of blood and there is optimal utilization of blood. High requirement of blood units, also corelates with previous studies, which show high demand of blood transfusion in cardiac surgeries (7) (8) (9).

In our study total 252 patients (both paediatric and adult) were included. We have included only CTVS interventions. Total 1006 units of PRBC were ordered and of which 784 units were issued from blood bank and were cross matched. Out of these 784 cross - matched units 60\% (472 units) were transfused to the patients. Mean transfusion Index (TI) was $1.87 \pm 0.55$, so we can say there is significant need of blood during the surgeries. MSBOS value is formulated by multiplying TI with Blood ordering quotient (BOQ). Our study shows a value of 2.8 for MSBOS for CTVS interventions.

In conclusion, the analysis of the actual blood usage and ordering data has helped us to drive, Crossmatch to Transfusion ratio $(\mathrm{C} / \mathrm{T})$, Transfusion Probability $(\mathrm{T} \%)$ and Transfusion Index (TI) for various surgical indications in Cardiothoracic \& Vascular surgery and provided evidence to formulate an effective MSBOS for their clinical conditions, this will go a long way towards strengthening patient care \& blood transfusion services in the institute. Also, it was observed that CTVS interventions are high blood transfusion demanding surgeries. The mean ordering units from blood bank was $3.19 \pm 0.32$ for CTVS interventions, and the formulated value of MSBOS was 2.8 .

\section{Conflict of Interest}

The authors of this study had no conflict of interest.

\section{References}

[1] World Health Organization (WHO). Blood Transfusion Safety [Internet].2021 [cited 2021 Aug 16]. Available from: https: //www.who. int/health topics/blood - transfusion - safety/\#tab=tab_1

[2] Rao GHR. Handbook of Blood Banking and Transfusion Medicine. Handbook of Blood Banking and Transfusion Medicine.2006.

[3] World Health Organization (WHO). Blood safety and availability [Internet].2020 [cited 2021 Aug 15]. Available from: https: //www.who. int/news room/fact - sheets/detail/blood - safety - and availability

[4] Silberstein LE, Kruskall MS, Stehling LC, Johnston MFM, Rutman RC, Samia CT, et al. Strategies for the Review of Transfusion Practices. JAMA [Internet].1989 Oct 13; 262 (14): 1993-7. Available from:

https:

//doi.

Volume 10 Issue 11, November 2021 
org/10.1001/jama.1989.03430140111034

[5] Friedman BA, Oberman HA, Chadwick AR, Kingdon KI. The maximum surgical blood order schedule and surgical blood use in the United States. Transfusion.1976; 16 (4): 380-7.

[6] Mead JH, Anthony CD, Sattler M. Hemotherapy in Elective Surgery. An Incidence Report, Review of the Literature, and Alternatives for Guideline Appraisal. Am J Clin Pathol [Internet].1980 Aug 1; 74 (2): 223-7. Available from: https: //doi. org/10.1093/ajcp/74.2.223

[7] Yeh TJ, Shelton L, Yeh TJ. Blood loss and bank blood requirement in coronary bypass surgery. Ann Thorac Surg.1978 Jul; 26 (1): 11-6.

[8] Geissler RG, Rotering H, Buddendick H, Franz D, Bunzemeier H, Roeder N, et al. Utilisation of Blood Components in Cardiac Surgery: A Single - Centre Retrospective Analysis with Regard to Diagnosis Related Procedures. Transfus Med Hemotherapy [Internet].2015; 42 (2): 75-82. Available from: https: //www.karger. com/DOI/10.1159/000377691

[9] Huang D, Chen C, Ming Y, Liu J, Zhou L, Zhang F, et al. Risk of massive blood product requirement in cardiac surgery: A large retrospective study from 2 heart centers. Medicine (Baltimore) [Internet].2019; 98 (5). Available from: https: //journals. lww. com/md journal/Fulltext/2019/02010/Risk_of_massive_blood_ product_requirement_in.26. aspx

Volume 10 Issue 11, November 2021 www.ijsr.net 